\title{
Unilateral impacted maxillary fourth molar associated with erupted third molar: Case report \& line of management
}

\author{
Dalia Mostafa El-Naggar ${ }^{1}$ and Mohamed Adel Raghib ${ }^{2}$ \\ ${ }^{1}$ Department of Prosthodontics, Faculty of Dentistry, Tanta University, Tanta, Egypt \\ ${ }^{2}$ Department of Orthodontics, Faculty of Dentistry, Tanta University, Tanta, Egypt
}

\begin{abstract}
Reports of impacted fourth molar and its relation with the third molar are not properly documented. This case report describes a case of unilateral impacted right maxillary fourth molar associated with fully erupted right maxillary third molar. The maxillary and mandibular third molars on the left side were completely impacted. The patient was complaining of right cheek biting. It was decided to extract the right maxillary third molar using ordinary local infiltration anaesthesia and to leave the other impacted third molars since they were causing no symptoms. The follow up of the patient, after 4 weeks, showed partial eruption of the maxillary right fourth molar tooth with the disappearance of the sign of cheek biting. It is concluded that simple extraction of erupted third molar may result in normal eruption of the impacted fourth molar. Thus surgical intervention could be avoided.
\end{abstract}

\section{Introduction}

Supernumerary teeth are additional teeth occurring in the dental arch in excess of the normal dental formulas for each quadrant [1]. They do not occur very frequently; values for their prevalence in the general population vary from $0.3 \%$ to $3.8 \%[2,3]$. Their prevalence is most common in the permanent dentition and they are most frequently found in the maxilla [1-5] and in males [6]. Supernumerary molars are divided into paramolars and distomolars. Distomolars (fourth molar) are located distal to the third molar [7]. Distomolar teeth very often are not visible in intraoral examination and are detected incidentally on radiographs [8].

There are several case reports describing impacted fourth molars. However, reports of impacted fourth molar and its relation with the adjacent third molar were not properly documented. This case report describes a case of unilateral maxillary impacted fourth molar associated with fully erupted adjacent third molar. The maxillary third molar on the other side and the mandibular third molars were completely impacted.

\section{Case report}

A 35 years old male came to our clinic complaining from right cheek biting. Clinical oral examination revealed lacerations on the inner mucosa of the right cheek and a distally erupted right maxillary third molar with no opposing mandibular third molar which was the only cause present to explain this traumatic cheek injury.

Routine radiographic examination revealed an un-erupted right fourth maxillary molar and an impacted right mandibular third molar (Figure 1). The left side showed impacted maxillary and mandibular third molars, with no fourth molars. The impacted maxillary and mandibular molars did not cause any symptoms.

It was decided to extract the right maxillary third molar using ordinary local anaesthesia by infiltration method and to leave the other impacted third molars since they were causing no symptoms.
The follow up of the patient, after 4 weeks, showed partial eruption of the maxillary right fourth molar tooth and there was no sign of cheek biting.

\section{Discussion}

Supernumerary teeth may cause several problems: such as malocclusion, cheek biting, delayed eruption, or prevent eruption of a tooth. They may also lead to aesthetic disharmony and functional distortion [9]. However, in this case the supernumerary fourth molar did not prevent the eruption of the third molar although all other quadrants of the patient's mouth showed impaction of the third molars.

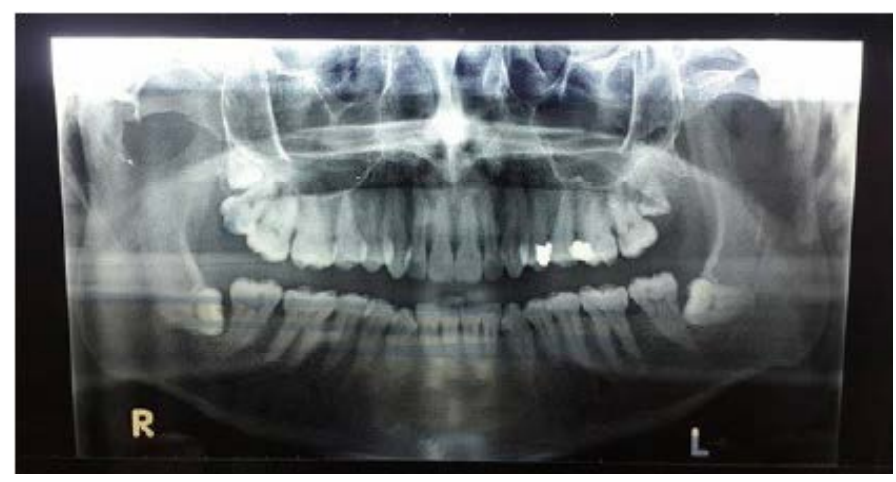

Figure 1. A panoramic radiograph showing right un-erupted maxillary forth molar with adjacent erupted third molar. The right mandibular third molar is impacted. On the left side it shows impacted maxillary and mandibular third molar with no fourth molars.

Correspondence to: Dr. Dalia M. El-Naggar, Department of Prosthodontics, Faculty of Dentistry, Tanta University, Tanta, Egypt, Tel: + (20) 1006790303 ; E-mail: daliaelnaggar@hotmail.com

Key words: eruption, extraction, impacted, management, molar

Received: October 06, 2016; Accepted: October 21, 2016; Published: October 25,2016 
Several reports in the literature described impacted fourth molar [1-5]. However; the description of the adjacent third molar was ignored. This case reports an impacted right maxillary fourth molar with an adjacent erupted third molar. The treatment of this case is usually performed by simple extraction of the right maxillary third molar and surgical extraction of the adjacent impacted fourth molar.

In this case it was decided to extract the maxillary right third molar, and to leave the maxillary right fourth molar to erupt normally as the patient was complaining of cheek biting only. The follow up of the patient for 4 weeks showed partial eruption of the maxillary right fourth molar tooth. The advantage of this approach is to avoid surgical intervention and encourage the migration of the fourth molar in a suitable position for avulsion $[2,10]$.

\section{Conclusion}

It could be concluded that simple extraction of erupted third molar should be considered in case of impacted fourth molar. Follow up of the patient may show normal eruption of the impacted fourth molar. Thus surgical intervention could be avoided.

\section{Acknowledgement}

The authors are grateful to Professor Adel Raghib, Department of Pathology, Faculty of Dentistry, Tanta University for his valuable clinical observations and suggested intervention. The authors are also grateful to Professor Mostafa El-Naggar, Department of Anatomy, Faculty of Medicine, Jazan University for his help in finalizing the manuscript.

\section{References}

1. Woelfel JB (1984) Dental Anatomy. (3rd edn), Philadelphia, Lea \&Fabiger 226-228.

2. Piattelli A, Tetè S (1992) Bilateral maxillary and mandibular fourth molars. Report of a case. Acta Stomatol Belg 89: 57-60.[Crossref]

3. Pindborg JJ (1970) Pathology of the dental hard tissues. Copenhagen.

4. Menardía-Pejuan V1, Berini-Aytés L, Gay-Escoda C (2000) Supernumerary molars. A review of 53 cases. Bull Group Int Rech Sci Stomatol Odontol 42: 101-105.[Crossref]

5. Yashiro M, Yosue T, Kai Y, Kawano T, Hosoi K, et al. (1987) [Radiographical study of supernumerary teeth with special reference to the upper molar region]. Shigaku 75: 1013-1021.[Crossref]

6. Kokten G, Balcioglu H, Buyukertan M (2003) Supernumerary fourth and fifth molars: a report of two cases. J Contemp Dent Pract 4: 67-76.[Crossref]

7. Shultsman M, Taicher S (2003) [Fourth molars in the maxilla and mandible--a rare phenomenon]. Refuat Hapeh Vehashinayim (1993) 20: 35-37, 80.[Crossref]

8. 8. Nagaveni N, Umashankara K, Radhika N, Praveen Reddy B, Manjunath S (2010) Maxillary paramolar: report of a case and literature review. Arch Orafac Sci 5: 24-8.

9. Rajab LD, Hamdan MA (2002) Supernumerary teeth: review of the literature and a survey of 152 cases. Int J Paediatr Dent 12: 244-254.[Crossref]

10. Koo S, Salvador PS, CiuffiJúnior J, de Silva Júnior AR (2002) Bilateral maxillary fourth molars and a supernumerary tooth in maxillary canine region--a case report SADJ 57: 404-406.[Crossref]

Copyright: $\mathbb{0} 2016$ El-Naggar DM. This is an open-access article distributed under the terms of the Creative Commons Attribution License, which permits unrestricted use, distribution, and reproduction in any medium, provided the original author and source are credited. 